\title{
Blue Color Change after Videothoracoscopic Sympathicotomy for Primary Palmar and Axillary Hyperhidrosis
}

\author{
Yusuf Kahyà $^{1}$, Bülent Mustafa Yenigün${ }^{1}$, Çiğdem Yıldırım Güçlü² and Ayten Kayı Cangır ${ }^{*}$ \\ ${ }^{1}$ Department of Thoracic Surgery, Ankara University School of Medicine, Turkey \\ ${ }^{2}$ Department of Anesthesiology and Reanimation, Ankara University School of Medicine, Turkey
}

*Corresponding author: Ayten Kayı Cangır, Ankara University School of Medicine, Ibni Sina Hospital, Department of Thoracic Surgery 06100 Sihhiye, Ankara, Turkey, Tel: +90-505-5025190; E-mail: Ayten.K.Cangir@medicine.ankara.edu.tr

\section{Keywords: Methemoglobinemia; Bupivacaine; Videothoracoscopic sympathicotomy}

Received Date: February 7, 2018; Accepted Date: February 13, 2018; Published Date: February 20, 2018

\section{Case Blog}

\section{Introduction}

In this study, we aimed to present a case of methemoglobinemia after bilateral uniport Videothoracoscopic Sympathectomy (VTS).

\section{Case Presentation}

A 21-year-old female patient underwent VTS at T2-3-4 levels after local anesthesia with $20 \mathrm{~mL} \mathrm{0.5 \%} \mathrm{bupivacaine} \mathrm{injection}$ (100 mg total) to bilateral third intercostal space and general anesthesia due to primary palmar and axillary hyperhidrosis (Figure 1). Cyanosis was inspected in the patient's nail at 5th hour postoperatively, the arterial blood gas analysis (ABG) was; pH: 7.42, PO2: 97.6 mmHg, PCO2: $31.2 \mathrm{mmHg}, \mathrm{SaO} 2:$ 98\%, and MetHb: 7.7\%.

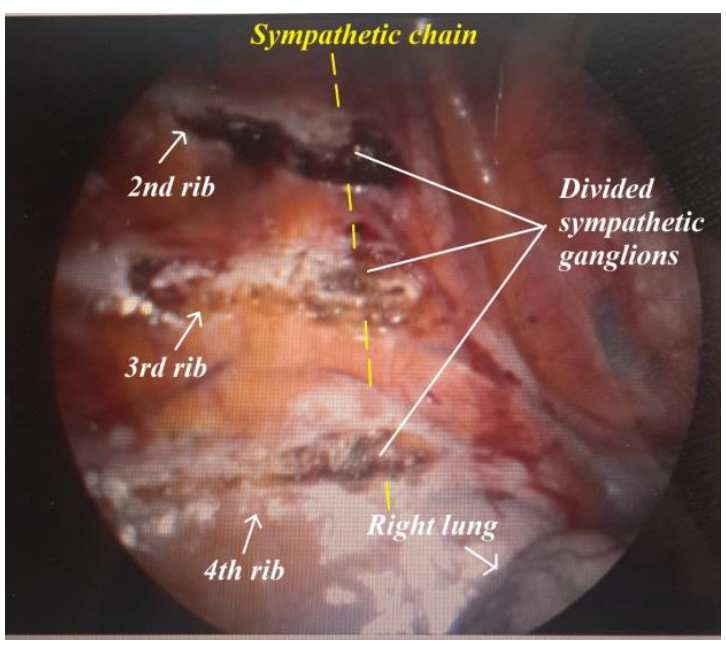

Figure1: İntraoperative view.

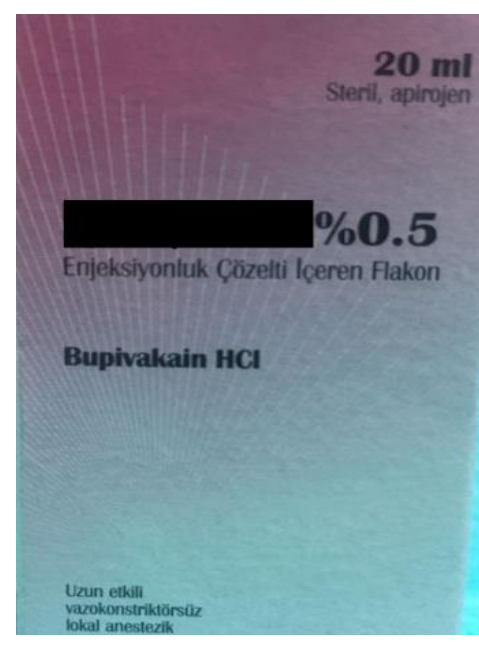

Figure 2: Preparation of Bupivacaine.

Citation: Kahya Y, Yenigün BM and Güçlü CY et al. Blue Color Change after Videothoracoscopic Sympathectomy for Primary Palmar and Axillary Hyperhidrosis. J Clin Cases Rep 2018: 1(1) 6-7. DOI: https://doi.org/10.46619/joccr.2018.1-1002 


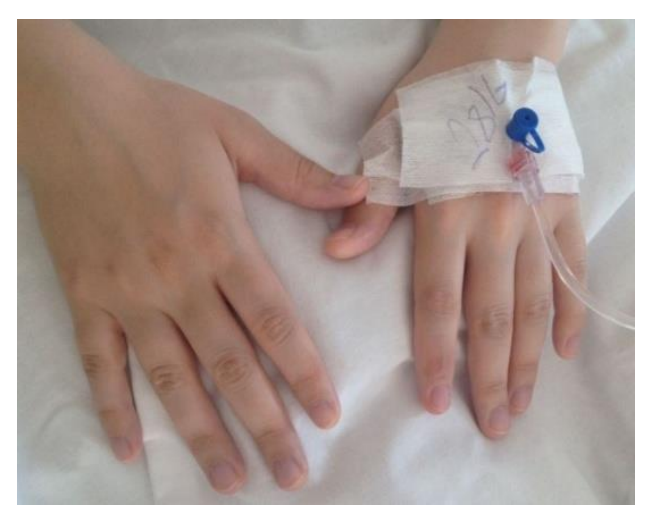

Figure 3: Cyanosis of the nails.

High-rate of MetHb in this case was diagnosed as bupivacaine induced methemoglobinemia by excluding other causes of cyanosis (Figure 2 and Figure 3).

After oxygen therapy (4 L/min) and ABG follow-ups, cyanosis of the case started to decline and MetHb was measured in the normal range at 12th hour ABG. Patient was discharged in postoperative 1st day.

\section{Discussion}

Methemoglobinemia is the clinical table showing the development of hypoxemia with the oxidation of hemoglobin iron, which is exposed to oxidants such as local anesthetics commonly used in surgical practice [1]. As noted in this case, methemoglobinemia should come to mind when unexpected cyanosis develops after local anesthetic use. In our department, this complication developed for the first time in 108 cases treated with VTS between 2005-2017 [2].

\section{References}

1. Guay J. (2009) Methemoglobinemia related to local anesthetics: a summary of 242 episodes. Anesth Analg 108(3): 837-845.

1. Schroeder TH, Dieterich HJ and Mühlbauer B. (1999) Methemoglobinemia after axillary block with bupivacaine and additional injection of lidocaine in the operative field. Acta Anaesthesiol Scand 43(4): 480-482. 